\title{
ACESSO À INFORMAÇÃO E TRANSPARÊNCIA: UMA ANÁLISE DOS PORTAIS DE TRANSPARÊNCIA DOS MUNICÍPIOS A PARTIR DO QUESTIONAMENTO QUANTO AOS PERCENTUAIS OBRIGATÓRIOS DE SAÚDE E EDUCAÇÃO
}

\author{
LOPES, A. I. S. ${ }^{1 ;}$ BITENCOURT, C. M.² \\ PALAVRAS CHAVE: Portais da transparência. Lei de Acesso à Informação. Cumprimento dos Percentuais \\ obrigatórios. Saúde. Educação.
}

\begin{abstract}
RESUMO
0 presente trabalho tem como escopo verificar se é possível, a partir dos portais de transparência dos municípios, conhecer acerca do cumprimento dos percentuais mínimos exigidos de $25 \%$ pra manutenção e desenvolvimento do ensino (MDE) e 15\% para ações e serviços públicos de saúde, para, de forma exemplificativa, discutir a transparência pública e seu cumprimento pelos municípios. Como base de pesquisa utilizou-se os 10 primeiros municípios premiados no ranking de Boas Práticas do TCE-RS, no ano de 2015 . Para buscar responder o problema proposto, primeiro se analisará a Lei de Acesso à Informação, e o que se denomina transparência ativa e passiva; em um segundo momento a análise dos rankings de transparência, e a forma como se optou pelo ranking do TCE. No último plano se encontra uma breve análise sobre a pesquisa acerca dos percentuais empregados pelos municípios, podendo constatar que todos cumpriram com as despesas obrigatórias, porém esse dado foi obtido por informações prestadas pelo TCE, ou seja, apesar de disporem da informação, é fato que os portais estão longe de realizar a efetiva transparência, uma vez que os dados estão postos de forma fragmentada, a informação não é organizada e perguntas simples como a que o presente estudo se propôs, não possuem subsídios para serem respondidas.
\end{abstract}

\section{INFORMATION ACCESS AND ACCOUNTABILITY: AN ANALYSIS OF THE CITIES ACCOUNTABILITY PORTALS QUESTIONING ABOUT THE REQUIRD PERCENTAGES OF HEALTH AND EDUCATION}

KEYWORDS: Accountability portals. Information Acess Law. Obligation constitucional percentual. Health. Education.

\begin{abstract}
This work has the scope to verify if it is possible from the municipalites accountability portals to determine the cities had accomplished the minimum required of $25 \%$ for education maintenance and development (MDE) and $15 \%$ for public health actions and services, for, in an exemplary way, discuss the public accountability and its compliance by the municipalities. As a base of the research, were used 10 first municipalities in the ranking of the most transparent in Rio Grande do Sul for the Good Practices Award of TCE-RS in the year of 2015. In order to answer the proposed problem, will be analyzed at first the Information Acess Law, which is called active and passive accountability; in a second moment the analysis of the accountability rankings, and the way the TCE ranking was chosen. In the last plan its a brief analysis of the research about the percentages used by the municipalities in health and education, verifying that all the cities fullfilled the compulsory expenses. However, this information wasn't provided from the portals but by TCE, despite having the information to achieve the dictates of the Information Acess Law, it is a fact that the portals are far from achieving effective accountability, once the data are put in a fragmented way, the information is not organized and questions the present study, do not have subsidies to be answered.
\end{abstract}

\footnotetext{
1 Acadêmico do curso de Direito na Universidade de Santa Cruz do Sul.

2 Docente do Departamento de Direito de na Universidade de Santa Cruz do Sul.
} 


\section{INTRODUÇÃO}

0 presente estudo está inserido no projeto Transparência e Acesso à Informação para o Exercício do Controle Social: um estudo dos portais da transparência dos municípios do Rio Grande do Sul com enfoque aos serviços públicos e políticas públicas de saúde e educação.

A pesquisa tem por problema central buscar dentre os municípios ranqueados como os mais transparentes definidos pelos prêmios de boas práticas, se é possível identificar a partir de seus portais o cumprimento dos percentuais obrigatórios dos orçamentos de saúde e educação? Obviamente tal análise passa pela discussão se a informação é prestada de forma acessível e transparente aos cidadãos. 0 objetivo é analisar criticamente se os portais de transparência têm cumprido os fins propostos, ou seja, propiciar aos cidadãos amplo acesso através da disposição de informações capazes de ser compreendidas pelos administrados, ao buscarem conhecimento sobre a atuação da administração pública. Para isso, buscou-se de forma exemplificativa analisar dois direitos de fundamental importância e que possuem um tratamento "diferenciado" no orçamento, uma vez que impõe ao gestor percentuais obrigatórios.

A hipótese positiva é a de que os municípios cumprem formalmente com as diretrizes da Lei de Acesso à Informação (Lei 12.527/2011) em relação ao objeto do problema proposto, gerando a transparência. A outra hipótese é a de que cumprem com o acesso à informação, mas não em termos transparentes, no sentido de clareza e objetividade a fim de gerar a comunicação os portais acabam se distanciando do fim proposto, ou seja, não é possível identificar a partir das informações prestadas se os mesmos cumprem com os percentuais obrigatórios em saúde e educação.

Pode-se dizer que a pesquisa será exploratória, na medida em que se busca abordar o fenômeno pelo levantamento de informações. Enquanto método de pesquisa optou-se pelo dedutivo, pois partindo-se do problema se os portais de informações cumprem com seus deveres constitucionais referentes a temática de saúde e educação, partiu-se de uma hipótese positiva e uma negativa na qual se buscou falsear ao longo da pesquisa exploratória.

Preliminarmente o trabalho abarcará uma análise sobre a Lei de Acesso à Informação, entrando nos pontos chaves do direito à informação, e trazendo as ferramentas que o legislador dispôs na Lei 12.527/11 para a busca das informações públicas. Em um segundo plano, analisará os rankings que serão utilizados para a seleção dos municípios e demonstrará os empecilhos e atribuições que auxiliaram na escolha da entidade fiscalizadora, no caso, o Tribunal de Contas do Estado do Rio Grande do Sul, ora denominado apenas como TCE/RS. No terceiro ponto de análise passará a investigar se a partir das informações dispostas nos portais é possível identificar nos casos de saúde e educação, se há informações e transparência quanto à obrigatoriedade dos percentuais de $15 \%$ e $25 \%$ respectivamente.

\section{LEI DE ACESSO À INFORMAÇÃO E A TRANSPARÊNCIA ATIVA E PASSIVA}

Traçando uma linha das leis que trouxeram como pauta a informação e a transparência da Administração Pública tem-se como uma das bases fortes a Lei de Responsabilidade Fiscal $n^{\circ} 101 / 2000$, que conforme os autores Bittencourt e Reck (2016, p. 8), a presente lei possui como grandes objetivos a perseguição das funções públicas de planejamento, transparência, controle e responsabilidade.

O texto da Lei de Responsabilidade Fiscal trouxe um arcabouço de prerrogativas em sua seção I, da Transparência da Gestão Fiscal, que em seu art. 48 enumera os meios dispostos para que os cidadãos possam ter conhecimento acerca dos atos da Administração, entre estes: participação popular, discussão dos planos das leis de diretrizes orçamentárias e orçamentos.

Segundo a Cartilha de Acesso à Informação (2011) outro grande passo para a transparência foi à criação dos Portais de Transparência que foi realizado em 2004, sendo gerenciados pela Contadoria Geral da União 
(www.transparência.gov.br). A criação dos portais veio em um momento de abertura do Estado para a transparência, e a realização deste:

\begin{abstract}
"é um importante elemento para o controle da gestão pública, uma vez que possibilita a prestação de contas, que é indispensável para que haja a eventual responsabilização daqueles que cometeram irregularidades no uso do dinheiro público (FREIRE, 2014, p. 67)."
\end{abstract}

E é nesse ínterim que ascende a Lei 12.527/2011, conhecida como Lei de Acesso à Informação possuindo regulamentação nos dispositivos do inciso XXXIII, art. $5^{\circ}$ (todos têm direito a receber dos órgãos públicos informações de seu interesse particular, ou de interesse coletivo ou geral, que serão prestadas no prazo da lei, sob pena de responsabilidade, ressalvadas aquelas cujo sigilo seja imprescindível à segurança da sociedade e do Estado) e inciso II, do §3 art. 37 (a lei disciplinará as formas de participação do usuário na administração pública direta e indireta, regulando especialmente: II - o acesso dos usuários a registros administrativos e a informações sobre atos de governo, observado o disposto no art. 5, X e XXXIII). A Cartilha de acesso à Informação (2011) preconiza que a Lei de Acesso à Informação trouxe ao direito brasileiro uma série de regulamentações e normas inovadoras no tocante ao acesso da população as informações públicas, de modo que traz uma mudança no sistema governamental brasileiro no que tange a transparência, tendo como uma de suas concepções de que o sigilo seria a exceção e a informação a regra.

Consoante Alves Júnior (2017, p. 57), no direito brasileiro no que concerne ao direito de acesso à informação, o Estado possui dois deveres: primeiramente de não interferir, mais precisamente um não fazer, no que toca ao direito dos cidadãos de buscar informações de origem pública, procurando não impedi-los de conhecer de qualquer informação de cunho social. E em um segundo plano o direito se consubstancia em um dever de fazer em que o Estado não teria a possibilidade de limitar a população, mas sim o dever de facilitar o acesso às informações difundindo de forma abrangente todos os atos realizados pela Administração.

O dever de fazer, de divulgar as informações da Administração Pública quando do nascimento da Lei de Acesso à informação, trouxe paradigmas ainda pouco conhecidos, assevera Deienno e Santos $(2014$, p. 18) que inclusive em âmbito internacional no que corresponde às regulamentações de direito à informação as leis de transparência ao redor do mundo apenas instituíram o dever de divulgação das informações públicas sobre o governo central, enquanto a lei brasileira foi mais audaciosa e proclamou que todos os poderes do Estado precisariam difundir as informações visto que são públicas. A regulação de que todos os poderes passariam pelo dever de informação levou o Brasil a colocação de trigésimo lugar com uma das leis de acesso à informação mais transparente do mundo entre outros noventa países segundo levantamento realizado pela Unesco, sendo uma boa posição visto ser uma lei muito recente (Disponível em: http://politica.estadao.com.br/noticias/eleicoes,lei-de-acesso-esta-entre-as-30-melhores-imp-,853010).

A regulamentação da Lei 12.527/2011 recebeu tão alto destaque devido a essa abrangência tão ampla, que conforme o Manual da Lei de Acesso à Informação (2013) engloba os três poderes definidos no art. $2^{\circ}$ da Constituição Federal, bem como todos os órgãos e entidades sendo Federais, Estaduais, Municipais ou Distritais, e ainda todos os órgãos da Administração Indireta e Direta. Ademais, ainda há abrangência sobre todas as entidades privadas que não possuem finalidades lucrativas, mas que recebem recursos públicos, não obstante a motivação para o uso das verbas públicas, constante art. $1^{\circ}$, da lei 12.527 de 18 de Novembro de 2011.

A Lei de Acesso à Informação (ou LAl como é comumente nomeada) trouxe tal qual apresenta Miragem (2013), deveres de conduta ao Estado, os quais se bifurcam em duas ferramentas que irão proporcionar o acesso à informação de maneira prática, a transparência ativa e a transparência passiva.

A LAI possui a obrigação de fazer os órgãos e entidades da Administração Pública divulgarem informações de cunho social por intuito próprio segundo os deveres de conduta da transparência ativa, Miragem disciplina ainda que essa conjuntura compreende uma obrigação de manter disponível de forma permanente todos os dados que possuírem significado sobre as informações difundidas no que compete aos atos da Administração Pública.

Corrobora o Manual da Lei de Acesso à Informação (2013) que essa modalidade de divulgação de informações nomeada de transparência ativa delega aos órgãos a atribuição de difundir as informações que sejam de 
interesse geral ou coletivo. A Lei 12.527/11 traz em seu artigo $8^{\circ}$, a premissa da transparência ativa, transcrevese dessa forma: "É dever dos órgãos e entidades públicas promover, independentemente de requerimentos, a divulgação em local de fácil acesso, no âmbito de suas competências, de informações de interesse coletivo ou geral por eles produzidas ou custodiadas".

Contudo, conforme pode-se ater do inciso II, art. $3^{\circ}$ :

[...] os procedimentos previstos nesta Lei destinam-se a assegurar o direito fundamental de acesso à informação e devem ser executados em conformidade com os princípios básicos da administração pública e com as seguintes diretrizes: II - divulgação de informações de interesse público, independentemente de solicitações.

0 texto do artigo traz o conhecimento de que a Lei de Acesso à Informação toda tem o intuito da transparência ativa, ou seja, as informações devem ser divulgadas de forma pró-ativa, sem a necessidade de solicitações aos órgãos e entidades da Administração.

Ocorre que a Lei 12.527/2011 também cria o mecanismo quando não há a divulgação da informação diretamente pela Administração, esta modalidade recebe o nome de transparência passiva, e atuará quando houver uma solicitação de determinada informação. A transparência passiva nada mais é, conforme o descrito por Deiene e Santos, que a circunstância na qual a sociedade demanda ao ente público a informação que deseja, sendo esta de caráter social ou público, não sendo o caso de sigilo. Os casos de sigilo são trazidos pelo art. 23 da LAl, e são tidos como conjunturas onde a divulgação da informação traria perigo a sociedade ou ao Estado.

A modalidade de informação da transparência passiva está contida no art. 10, sendo que "qualquer interessado poderá apresentar pedido de acesso a informações aos órgãos e entidades referidos no art. 10 desta Lei, por qualquer meio legítimo, devendo o pedido conter a identificação do requerente e a especificação da informação requerida". Constante o art. 10, o estado possui a obrigação de garantir que as perguntas solicitadas sejam atendidas pelo poder público.

Para que possam ser atendidas todas as solicitações realizadas em tempo hábil, a Controladoria Geral da União (CGU) criou um centro de atendimento denominado de Serviço de Informação ao Cidadão (http://www.acessoainformacao.gov.br/), também conhecido como SICs, "é um sistema que funciona como porta de entrada para as informações, a fim de organizar e facilitar o acesso" (Manual de Acesso à Informação, 2013, p. 11).

Nesse primeiro plano buscou-se contextualizar uma linha temporal de uma série de regulamentações que veio a salvaguardar o acesso à informação, e a criação da lei 12.527/2011 como uma das grandes premissas dessa busca. 0 próximo capítulo busca conhecer os rankings que se destinam a premiar os municípios mais transparentes, e dentro dessa escolha se dará a pesquisa dos mecanismos de transparência ativa e passiva para a busca dos percentuais obrigatórios de saúde e educação nos portais dos municípios premiados.

\section{COMO SE DEU A ESCOLHA DO RANKING DE MUNICÍPIOS QUANTO À TRANSPARÊNCIA}

A pesquisa sobre o estudo dos rankings é realizado pelas seguintes organizações: a Controladoria Geral da União (CGU), o Ministério Público Federal (MPF-RS) e o Tribunal de Contas do Rio Grande do Sul (TCE-RS). A busca pelos rankings para as finalidades que persegue a pesquisa em questão abarcou o período anual de 2015 (eleito o ano de 2015 visto a pesquisa ter iniciado antes dos dados dos demais anos estarem completos com os respectivos rankings).

Observa-se primariamente o Tribunal de Contas do Estado, o qual realiza duas avaliações nos sites do legislativo e executivo dos municípios, inquirindo 22 perguntas (convém salientar que são 20 perguntas ao Executivo e 2 ao legislativo), e contendo um total de 88 itens avaliados. A pesquisa do ente analisa 497 cidades, em suma a integralidade dos municípios do Rio Grande do Sul, utilizando as normas da Lei de Responsabilidade Fiscal (Lei 
131/2009), da Lei de Acesso à informação (Lei 12.527/2011) e do Decreto Federal responsável por determinar o padrão mínimo de qualidade da administração financeira (Decreto 7.185/2010).

Sendo que estes seriam os critérios aplicados pelo TCE-RS:

1) Pedido de informações por meio da Internet; 2) Relatório de pedidos de informação; 3) Informações organizacionais; 4) Registro de repasses ou transferências; 5) Registro de despesas; 6) Registro de receitas; 7) Relatórios da transparência da gestão fiscal; 8) Informações sobre licitações e seus editais e resultados; 9) Informações sobre contratos celebrados; 10) Dados gerais para acompanhamento de programas, ações, projetos e obras; 11) Administração do patrimônio público - Imóveis 12) Administração do patrimônio público - Veículos; 13) Recursos Humanos; 14) Diárias; 15) Publicação de respostas a perguntas mais frequentes; 16) Ferramenta de pesquisa; 17) Canal de comunicação com o cidadão ("Fale Conosco" Ouvidoria); 18) Medidas para garantir atendimento a usuários com necessidade especiais; 19) Instrumento Normativo local que regulamente a LAl; 20) Serviços e atividades de interesse coletivo - Executivo;

Consoante Manfio (2017) os sítios premiados foram aqueles que preencheram ambos os requisitos elencados: I) Receberam nota mínima de 70 pontos, de um máximo de 100; II) atenderam de forma ao menos parcial os aspectos acerca dos pedidos de informações, tais como despesas, licitações e contratos (Disponível: http://portal.tce.rs.gov.br/docs/transparencia_2015/relatorio_premio_boas_praticas_2015.pdf. Acesso em 25 de Agosto de 2017).

No que concerne a Controladoria Geral da União, com o ranking nomeado de A Escala Brasil Transparente, há um questionário que é realizado por um avaliador o qual perfaz uma análise de 12 quesitos que abordam 15 perguntas, relacionadas ao acesso à informação e ao Serviço de Informação ao Cidadão (SIC). Entretanto a amostragem se dá apenas em parte do Estado do Rio Grande do Sul, atingido uma totalidade de 149 municípios (Disponível em: http://www.cgu.gov.br/assuntos/transparencia-publica/escala-brasil-transparente/metodologia. Acesso em 10 de Julho de 2018).

A Controladoria Geral da União apresenta os seguintes requisitos:

1) 0 regulamento foi localizado na página eletrônica? 2) 0 ente regulamentou a LAI? 3) Regulamentou a criação do SIC? 4) Existe a previsão da autoridades que podem classificar a informação quanto ao grau de sigilo? 5) Previsão de responsabilização do servidor em caso de condutas ilícitas; 6) Regulamentou a existência de pelo menos uma instância recursal? 7) Existe indicação precisa no site de funcionamento de um SIC físico, ou seja, com a possibilidade de entrega de um pedido de acesso de forma presencial? 8) Há alternativa de enviar pedidos de forma eletrônica ao SIC? 9) Para fazer a solicitação, são exigidos dados de identificação do requerente que dificultem ou impossibilitem o acesso à informação? 10) Apresenta possibilidade de acompanhamento posterior da solicitação? 11) Cumpre os prazos para resposta das solicitações? 12) Respondeu ao que se perguntou, atendendo ao pedido de informação?

Já no que consta ao Ministério Público Federal (MPF), este possui um ranking com 16 critérios que se desdobram em 32 perguntas, o método de análise do MPF é realizado em dois momentos: de forma preliminar após a primeira avaliação é enviado uma recomendação aos municípios que tiveram nota abaixo do esperado na colocação, sendo que decorrido o prazo de cento e vinte dias é realizado nova avaliação dos municípios (Disponível em: http://combateacorrupcao.mpf.mp.br/ranking/pontuacao/ranking/o-projeto-new. Acesso em 15 de Julho de 2015).

Critérios elaborados pelo Ministério Público Federal:

1) 0 ente possui informações sobre Transparência na internet? 2) 0 Site contém ferramenta de pesquisa de conteúdo que permita o acesso à informação? 3) Há informações sobre a receita nos últimos 6 meses, incluindo natureza, valor de previsão e valor arrecadado? 4) As despesas apresentam dados dos últimos 6 meses contendo: 5) 0 site apresenta dados nos últimos 6 meses contendo: 6) 0 ente divulga as seguintes informações concernentes a procedimentos licitatórios com dados dos últimos 6 meses? 7) 0 site apresenta: As prestações de contas (relatório de gestão) do ano anterior; Relatório Resumido da Execução Orçamentária (RREO) dos últimos 6 meses; Relatório de Gestão Fiscal (RGF) dos últimos 6 meses; Relatório estatístico contendo a quantidade de pedidos de informação recebidos, atendidos e indeferidos, bem como informações genéricas sobre os solicitantes; 8) 0 Site possibilita a gravação de relatórios em diversos formatos eletrônicos, abertos e não proprietários, tais como planilhas e texto (CSV), de modo a facilitar a análise das informações? 9) Possibilidade de entrega de um pedido de acesso de forma presencial 10) Há possibilidade de envio de pedidos de informação de forma eletrônica (e-SIC)? 11) Apresenta possibilidade de acompanhamento posterior da solicitação? 12) A solicitação por meio do e-SIC é simples, ou seja, sem a exigência de itens de identificação do requerente que dificultem ou impossibilitem o acesso à informação, tais como: envio de documentos, assinatura reconhecida, declaração de responsabilidade, maioridade? 13) 
No site está disponibilizado o registro das competências e estrutura organizacional do ente? 14) 0 Portal disponibiliza endereços e telefones das respectivas unidades e horários de atendimento ao público? 15) Há divulgação de remuneração individualizada por nome do agente público? 16) Há divulgação de Diárias e passagens por nome de favorecido e constando, data, destino, cargo e motivo da viagem?

Em análise aos três rankings, observa-se que a CGU não engloba todas as cidades gaúchas, o que poderia vir a inviabilizar o estudo dada a parcialidade na elaboração do ranking, bem como possui um número de questionário menor que as dos demais rankings observados, visto que o Ministério Público Federal possui uma gama de 16 critérios que se desdobram em 32 questões, já o TCE possui uma quantidade de 88 critérios avaliativos.

Assim, diante dos dados trazidos a tona é possível notar uma maior amplitude dos critérios utilizados pelo Tribunal de Contas do Estado, que utiliza mais itens para aplicar um grau de transparência aos municípios indicando-os no ranking, mais especificamente no prêmio de Boas Práticas na Internet no ano de 2015. Desse modo, conforme as notas atribuídas aos municípios, temos do primeiro ao último colocado: Porto Alegre, Novo Hamburgo, Canoas, Picada Café, Passo Fundo, Venâncio Aires, Farroupilha, São Pedro do Sul, Ipê e Feliz.

Diante do conhecimento dos 10 municípios tidos como os mais transparentes do Estado, conforme o ranking realizado pelo TCE-RS passa-se a uma análise dos setores de educação e saúde, mais especificamente no atendimento dos percentuais constitucionais obrigatórios definidos pela Constituição Federal, e quanto a transparência dos sítios dos municípios com o objetivo de constatar se há a aplicação das verbas mínimas para às áreas e se os portais estão revelando de forma completa as informações sobre esses dados.

\section{O CUMPRIMENTO QUANTO AOS PERCENTUAIS OBRIGATÓRIOS EM MATÉRIA DE EDUCAÇÃO E SAÚDE EM CONFORMIDADE COM A EMENDA CONSTITUCIONAL 29/2002 E A LEI COMPLEMENTAR 141/2012}

A partir da escolha do ranking do Tribunal de Contas do Estado, na sua premiação denominada de Boas Práticas na Internet no ano de 2015, temos os seguintes municípios ocupando as primeiras dez colocações por ordem decrescente: Porto Alegre, Novo Hamburgo, Canoas, Picada Café, Passo Fundo, Venâncio Aires, Farroupilha, São Pedro do Sul, Ipê e Feliz.

Nesse teor, salienta-se que as cidades foram escolhidas devido a sua posição no quesito transparência, o qual é o conceito principal do projeto. 0 estudo incidirá sobre as cidades na busca pelas pastas de saúde e educação no intuito de averiguar se é possível identificar se ocorreu o cumprimento dos percentuais constitucionais que são aplicados nas rubricas de saúde e educação, dado a Emenda Constitucional 29/2002.

Diante do exposto, elucida-se que os gestores precisam perseguir uma meta de dispêndios das receitas públicas, o qual é expresso de forma anterior ao inicio do ano nas dotações do orçamento. Conforme explana Leite (2011), o orçamento seria uma "fonte de obrigações para a Administração", que a incumbe de cumprir termos já fixados as normas que ditarão a forma com que serão utilizadas as receitas orçamentárias.

Na legislação brasileira conforme é explanado por Pscitelli (2014), restou estabelecido que haveria uma despesa mínima que deveria ser cumprida pelos administradores, a qual consiste nas importantes áreas das políticas públicas de saúde e educação. Nesse sentido no que concerne à categoria educação, encontra-se na Carta Magna os pressupostos que devem ser atendidos no orçamento anual para a concretização da manutenção e desenvolvimento do Ensino (MDE), consoante o que se transcreve de forma tal qual o texto:

Art. 212. A União aplicará, anualmente, nunca menos de dezoito, e os Estados, o Distrito Federal e os Municípios vinte e cinco por cento, no mínimo, da receita resultante de impostos, compreendida a proveniente de transferências, na manutenção e desenvolvimento do ensino.

Entre esses 25\% destinados para as despesas em educação, a Lei de Diretrizes e Bases da Educação Nacional, Lei 9.934/96, define em seu art. 70 quais seriam os itens que pertenceriam ao cálculo da rubrica, transcreve-se aqui: 
Art. 70. Considerar-se-ão como de manutenção e desenvolvimento do ensino as despesas realizadas com vistas à consecução dos objetivos básicos das instituições educacionais de todos os níveis, compreendendo as que se destinam a: I - remuneração e aperfeiçoamento do pessoal docente e demais profissionais da educação; II - aquisição, manutenção, construção e conservação de instalações e equipamentos necessários ao ensino; III - uso e manutenção de bens e serviços vinculados ao ensino; IV - levantamentos estatísticos, estudos e pesquisas visando precipuamente ao aprimoramento da qualidade e à expansão do ensino; V realização de atividades-meio necessárias ao funcionamento dos sistemas de ensino; VI - concessão de bolsas de estudo a alunos de escolas públicas e privadas; VII - amortização e custeio de operações de crédito destinadas a atender ao disposto nos incisos deste artigo; VIII - aquisição de material didático-escolar e manutenção de programas de transporte escolar.

E em seu art. 71, os gastos que não poderiam caracterizar despesas da área, quais sejam:

[...] I - pesquisa, quando não vinculada às instituições de ensino, ou, quando efetivada fora dos sistemas de ensino, que não vise, precipuamente, ao aprimoramento de sua qualidade ou à sua expansão; II - subvenção a instituições públicas ou privadas de caráter assistencial, desportivo ou cultural; III - formação de quadros especiais para a administração pública, sejam militares ou civis, inclusive diplomáticos; IV - programas suplementares de alimentação, assistência médico-odontológica, farmacêutica e psicológica, e outras formas de assistência social; V - obras de infra-estrutura, ainda que realizadas para beneficiar direta ou indiretamente a rede escolar; VI - pessoal docente e demais trabalhadores da educação, quando em desvio de função ou em atividade alheia à manutenção e desenvolvimento do ensino.

Acerca das políticas públicas relativas às ações e serviços públicas de saúde (ASPS), recebem amparo jurídico na Constituição Federal no inciso $3^{\circ}$, art. 198, mas desenvolve-se na Lei Complementar 141/2012:

Art. $7^{\circ}$ Os Municípios e o Distrito Federal aplicarão anualmente em ações e serviços públicos de saúde, no mínimo, 15\% (quinze por cento) da arrecadação dos impostos a que se refere o art. 156 e dos recursos de que tratam o art. 158 e a alínea "b" do inciso I do caput e o $\S 3^{\circ}$ do art. 159, todos da Constituição Federal.

Observa a autora Pscitelli que os dispêndios mínimos com saúde não foram abordados quando da elaboração da Constituição democrática de 1988, e sim incluídos devido a Emenda Constitucional 29/2000, que objetivou "aos Estados, Distrito Federal e Municípios a aplicação de percentuais mínimos, calculados sobre sua receita de impostos" (p. 74, 2014).

A Lei Complementar 141/2012, regula também em seu art. $3^{\circ}$ e $4^{\circ}$ quais são os dispêndios que podem ser alocados como despesas referentes a rubricas de saúde e quais não poderiam ser considerados para esse cálculo. Sendo segundo o art. $3^{\circ}$ :

[...] serão consideradas despesas com ações e serviços públicos de saúde as referentes a: I - vigilância em saúde, incluindo a epidemiológica e a sanitária; II - atenção integral e universal à saúde em todos os níveis de complexidade, incluindo assistência terapêutica e recuperação de deficiências nutricionais; III capacitação do pessoal de saúde do Sistema Único de Saúde (SUS); IV - desenvolvimento científico e tecnológico e controle de qualidade promovidos por instituições do SUS; V - produção, aquisição e distribuição de insumos específicos dos serviços de saúde do SUS, tais como: imunobiológicos, sangue e hemoderivados, medicamentos e equipamentos médico-odontológicos; VI - saneamento básico de domicílios ou de pequenas comunidades, desde que seja aprovado pelo Conselho de Saúde do ente da Federação financiador da ação e esteja de acordo com as diretrizes das demais determinações previstas nesta Lei Complementar; VII - saneamento básico dos distritos sanitários especiais indígenas e de comunidades remanescentes de quilombos; VIII - manejo ambiental vinculado diretamente ao controle de vetores de doenças; IX - investimento na rede física do SUS, incluindo a execução de obras de recuperação, reforma, ampliação e construção de estabelecimentos públicos de saúde; $X$ - remuneração do pessoal ativo da área de saúde em atividade nas ações de que trata este artigo, incluindo os encargos sociais; $\mathrm{XI}$ acõos de apoio administrativo realizadas pelas instituições públicas do SUS e imprescindíveis à execução das ações e serviços públicos de saúde; e XII - gestão do sistema público de saúde e operação de unidades prestadoras de serviços públicos de saúde.

E consoante 0 art. $4^{\circ}$, não constituirão:

[...] I - pagamento de aposentadorias e pensões, inclusive dos servidores da saúde; II - pessoal ativo da área de saúde quando em atividade alheia à referida área; III - assistência à saúde que não atenda ao princípio de acesso universal; IV - merenda escolar e outros programas de alimentação, ainda que executados em unidades do SUS, ressalvando-se o disposto no inciso II do art. 3o; V - saneamento básico, inclusive quanto às ações financiadas e mantidas com recursos provenientes de taxas, tarifas ou preços públicos instituídos para essa finalidade; VI - limpeza urbana e remoção de resíduos; VII - preservação e correção do meio ambiente, realizadas pelos órgãos de meio ambiente dos entes da Federação ou por entidades não governamentais; VIII - ações de assistência social; IX - obras de infraestrutura, ainda que realizadas para beneficiar direta ou indiretamente a rede de saúde; e $X$ - ações e serviços públicos de saúde custeados com recursos distintos dos especificados na base de cálculo definida nesta Lei Complementar ou vinculados a fundos específicos distintos daqueles da saúde. 
Dada a análise realizada, pode-se conhecer que os municípios, conforme as leis vigentes, devem ter despesas na pasta referente a educação no patamar de $25 \%$, enquanto acerca da pasta de saúde revelam-se no percentual de $15 \%$ consoante a receita de impostos recebidos, não podendo ser quaisquer despesas contabilizadas nesse percentual mínimo.

A partir desse conhecimento parte-se para a prática em conhecer desses números nos portais de transparência dos 10 municípios premiados, acessando o portal de transparência das respectivas cidades. Uma primeira constatação observou-se que os municípios disponibilizam as informações em seus sítios, de forma proativa se utilizando da transparência ativa na difusão das informações. Ocorre que os portais dos municípios não expõem com a clareza e o rigor regulamentados por lei as informações prestadas em seus sítios, tal qual o município de Porto Alegre que na rubrica de saúde não é possível acessar a despesa de "Obrigações Patronais" de maneira que se torna impossível conhecer do recurso utilizado para aquele gasto, inviabilizando a possibilidade de fazer uma distinção conforme o regulamento da Lei Complementar 141/2012 (Disponível em: http://portaltransparencia.procempa.com.br/portalTransparencia/despPorOrgaoNaturezaPesquisa.doc).

Já o município de Passo Fundo conta com um sistema onde é possível adentrar nas rubricas e conhecer a fonte do recurso de cada dispêndio, apurando se o gasto realizado coincide com o disposto para a saúde ou para a educação. Toma-se como exemplo a rubrica de saúde no quesito de despesas com Material, Bem ou serviço, no tocante em que entrando na página de acesso identifica-se o recurso como sendo ASPS, sendo este um dos itens dispostos na Lei Complementar 141/2012 passíveis de serem adquiridos com o recurso (Disponível em: http://sig.pmpf.rs.gov.br/grp/acessoexterno/programaAcessoExternoPortal.faces Acesso em: 20.agosto.2017).

Além desse fato não existe página de acesso contendo o somatório dos percentuais obrigatórios que foram despendidos pelas cidades nos portais de transparência, o que facilitaria a procura dos cidadãos por esses dados. Enfim, mesmo sendo uma obrigação constitucional de aplicação mínima de recursos, os municípios não expõem informações tão substanciais.

Diante do exposto, as informações sobre os percentuais constitucionais apenas puderam ser encontradas no sítio do Tribunal de Contas do Rio Grande do Sul, que mantém uma lista com os percentuais mínimos:

\begin{tabular}{|c|c|c|}
\hline Cidade (Ranking Tce-rs) & $\begin{array}{c}\text { Educação 2015 (\% } \\
\text { MDE) }\end{array}$ & Saúde 2015 (\% ASPS) \\
\hline 1. Porto Alegre & $27,51 \%$ & $20,53 \%$ \\
\hline 2. Novo Hamburgo & $25,61 \%$ & $17,51 \%$ \\
\hline 3. Canoas & $29,74 \%$ & $16,92 \%$ \\
\hline $4 . \quad$ Picada Café & $29,95 \%$ & $17,92 \%$ \\
\hline 5. Passo Fundo & $35,15 \%$ & $18,56 \%$ \\
\hline 6. Venâncio Aires & $25,62 \%$ & $19,58 \%$ \\
\hline 7. Farroupilha & $30,93 \%$ & $18,04 \%$ \\
\hline 8. São Pedro do Sul & $25,15 \%$ & $21,94 \%$ \\
\hline 9. Ipê & $25,27 \%$ & $15,30 \%$ \\
\hline 10. Feliz & $26,20 \%$ & $19,69 \%$ \\
\hline
\end{tabular}

De acordo com os dados trazidos na tabela, é possível constatar que todos os municípios corresponderiam ao repasse mínimo exigido, todavia não há a confirmação se esses dados refletem os percentuais mínimos obrigatórios, uma vez que o TCE não traz a informação exposta se são dados que podem ser contabilizados para as despesas do mínimo obrigatório ou se são todos os dispêndios realizados pelo município, assim se desconhece a realidade das despesas e se estariam conforme o que preconiza a Lei de Diretrizes e Bases da Educação e a Lei Complementar 141/2012.

\section{RESULTADOS E DISCUSSÕES}

A Administração pública passou de uma era de segredo nos períodos ditatoriais em que as informações públicas eram restringidas apenas ao governo, para uma sociedade democrática na qual a informação é o escopo de uma boa administração. E neste breve trabalho busca-se trazer os parâmetros que se realocam a essa nova era de 
informação, em virtude de que há toda uma estrutura para que se efetive a vontade dos cidadãos em conhecer dos dados da Administração.

Esse conhecimento dos cidadãos nada mais é do que o controle social sobre os atos do governo no comando da coisa pública, e é nesse viés que o trabalho se insere no intuito de conhecer da transparência administrativa, e utilizar como ponto as rubricas de saúde e educação.

A partir da pesquisa elaborada chega-se a conclusão de que há municípios que ainda tem muito a crescer na disseminação das informações, no quesito que apenas dispor os valores referentes a uma rubrica não é o suficiente pra constituir uma informação sólida, é necessário que se possa conhecer de dados mais minuciosos, como a fonte de recurso utilizado, a qual se prestaria para contabilizar o mínimo obrigatório das exigências constitucionais. Sem essas informações o portal da transparência não é um meio que faça jus a denominação que carrega de transparente.

No tocante as despesas obrigatórias, segundo os dados do TCE houve o cumprimento de todos os municípios, entretanto a informação não é segura porque não se tem conhecimento da base de cálculo do TCE, se os dados que foram utilizados seriam apenas aqueles contados como ASPS, no caso de saúde, ou MDE no caso de educação, estariam corretos, porém podem ser todas as despesas elencadas nesse setor no munícipio e isso não coincidiria com a regulamentação. De forma que a proposta da pesquisa não pode ser atendida, tendo em vista que não houve confiança nos dados dispostos pelas instituições.

Ainda, os portais de transparência não condizem com as ferramentas que deveriam ser no auxilio ao controle social, uma vez que não dispõem de forma prática de algo tão importante quanto as despesas obrigatórias, sendo necessário que os municípios tivessem uma página expondo os dispêndios com saúde e educação, possibilitando assim ver cada despesa que os municípios alocassem como sendo dessa pasta.

Por fim, as informações trazidas garantem que ainda há muito a ser feito para que as ferramentas para a utilização do controle social se tornem efetivas, mas os princípios básicos de transparência e informação administrativa já começam a aparecer, redirecionando para uma era de acesso à informação.

\section{REFERÊNCIAS}

ALMEIDA, Herivelto; LEHFELD, Lucas de Souza; GUEDES, Mario Bulgarelli (Org). Comentários a Lei de Acesso à Informação. Santa Cruz do Sul: Editora Essere nel mondo, 2014.

ACESSO À INFORMAÇAO. Disponível em: http://www.acessoainformacao.gov.br/. Acesso em 20 de Novembro de 2017.

BRASIL. Constituição da República Federativa do Brasil, 1988. Disponível em:

<http://www.planalto.gov.br/ccivil_03/Constituicao/Constituicao.htm> Acesso em: 12 de jul. de 2017. . Emenda Constitucional 29, de 13 de setembro de 2000.

Altera os arts. 34, 35, 156, 160, 167 e 198 da Constituição Federal e acrescenta artigo ao Ato das Disposições

Constitucionais Transitórias, para assegurar os recursos mínimos para o financiamento das ações e serviços públicos de saúde. Diário Oficial [da] República Federativa do Brasil, Brasílio, DF. Disponível em:

<http://www.planalto.gov.br/ccivil_03/constituicao/emendas/emc/emc29.htm> Acesso em: 18.Jun.2017. . Lei $\mathrm{n}^{\circ}$ 12.527, de 18 de novembro de 2011. Diário Oficial [da] República Federativa do Brasil, Brasília, DF, 18 nov. 2011. Disponivel em: www.planalto.gov.br/ccivil_03/_ato2011-2014/2011/lei/l12527.htm. Acesso em: 10 Set. 2017. . Lei Complementar $n^{\circ} 141$, de 13 de janeiro de 2012. Diário Oficial [da] República Federativa do Brasil, Brasília, DF, 13 de janeiro de 2012. Disponível em: http://www.planalto.gov.br/ccivil_03/leis/lcp/Icp141.htm. Acesso em: 10 de set. de 2017.

. Lei Complementar $n^{\circ} 101$, de 4 de maio de 2000. Estabelece normas de finanças públicas voltadas para a responsabilidade na gestão fiscal e dá outras providências. Diário Oficial [da]República Federativa do Brasil, Brasília, DF, 05 mai. 2000. Disponível em:www.planalto.gov.br/ccivil_03/leis/LCP/Lcp101.htm. Acesso em: 27 set. 2017.

. Lei Complementar $n^{\circ}$ 131, de 27 de maio de 2009. Diário Oficial [da] República Federativa do Brasil, Brasília, DF, 28 maio 2009. Disponível em: www.planalto.gov.br/ccivil_03/leis/LCP/Lcp131.htm.Acesso em: 28 set. 2017. CONTROLADORIA GERAL DA UNIÃO. Cartilha de Acesso a Informação: Uma Introdução a Lei $n^{\circ} 12.527$, de 18 de Novembro de 2011. Disponível em: http://www.acessoainformacao.gov.br/central-deconteudo/publicacoes/arquivos/cartilhaacessoainformacao.pdf. Acesso em 9 Set. 2017

. Manual de Acesso a Lei da Informação para Estados e Municípios. Disponível em:http://www.cgu.gov.br/Publicacoes/transparencia-publica/brasiltransparente/arquivos/manual_lai_estadosmunicipios.pdf ESCALA BRASIL TRANSPARENTE. Disponivel em: http://www.cgu.gov.br/assuntos/transparencia-publica/escala-brasiltransparente/metodologia. Acesso em 10 Out. 2017. 
FREIRE, Felipe Ribeiro. Desafios para a transparência pública: Um estudo com usuários do Portal da Transparência do Governo Federal. 2014, 284 fl. Dissertação (Mestrado em Direito). Universidade de Brasília, Instituto de Ciência Política, 2014. MANFIO, Vinicius. Os critérios definidores da transparência: uma análise dos rankings de transparência elaborados pelo TCERS, MPF E CGU.[S.I]:2017. Não publicado.

MARTINS, Paula Lígia. Acesso à informação: Um direito fundamental e instrumental. Acervo: Rio de Janeiro, 2011

MIRAGEM, Bruno. A nova administração pública e o direito administrativo. 2 ed. São Paulo: Editora dos Tribunais, 2013.

MÜLLER, Caroline Bittencourt; RECK, Janriê Rodrigues. Controle da Transparência na contratação pública no Brasil - o acesso à informação como forma de viabilizar o controle social da Administração Pública. Revista do Direito, Santa Cruz do Sul, v. 2 , n. 49, p. 96-115, maio 2016, ISSN 1982-9957.

NUNES JÚNIOR, Flávio Martin Alves. Curso de Direito Constitucional. São Paulo: Editora dos Tribunais, 2017.

PISCITELLI, Tathiane. Direito Financeiro Esquematizado. 4.ed. São Paulo: Editora Método, 2014.

TRANSPARÊNCIA E CONTROLADORIA GERAL DA UNIÃO 2015: Ranking de cumprimento da Lei de Acesso à Informação. Disponível em <http://www.cgu.gov.br/assuntos/transparencia-publica/escala-brasil-transparente/metodologia> Acesso em: 18 Jul.2017.

TRIBUNAL DE CONTAS DO ESTADO DO RIO GRANDE DO SUL 2015: Prêmio de Transparência na Internet. Disponível em: < http://portal.tce.rs.gov.br/docs/transparencia_2015/relatorio_premio_boas_praticas_2015.pdf >. Acesso em: 18 Jun.2017. 